\title{
Trend Analysis of Pet Plants Before and After COVID-19 Outbreak Using Topic Modeling: Focusing on Big Data of News Articles from 2018 to 2021
}

\author{
Yumin Park ${ }^{1,3}$ and Yong-Wook Shin $1,2,3^{*}$ \\ ${ }^{1}$ Doctoral Student, Department of Plant Resources, Gyeongsang National University, Jinju 52725, Republic of Korea \\ ${ }^{2}$ Professor, Department of Plant \& Biomaterials science, Gyeongsang National University, Jinju 52725, Republic of Korea \\ ${ }^{3}$ Institute of Agriculture \& Life Science, Gyeongsang National University, Jinju 52828, Republic of Korea
}

\section{ABSTRACT}

Background and objective: The ongoing COVID-19 pandemic restricted daily life, forcing people to spend time indoors. With the growing interest in mental health issues and residential environments, 'pet plants' have been receiving attention during the unprecedented social distancing measures. This study aims to analyze the change in trends of pet plants before and during the COVID-19 pandemic and provide basic data for studies related to pet plants and directions of future development.

Methods: A total of 2,016 news articles using the keyword 'pet plants' were collected on Naver News from January 1, 2018 to August 15, 2019 (609 articles) and January 1, 2020 to August 15, 2021 (1,407 articles). The texts were tokenized into words using KoNLPy package, ultimately coming up with 63,597 words. The analyses included frequency of keywords and topic modeling based on Latent Dirichlet Allocation (LDA) to identify the inherent meanings of related words and each topic. Results: Topic modeling generated three topics in each period (before and during the COVID-19), and the results showed that pet plants in daily life have become the object of 'emotional support' and 'healing' during social distancing. In particular, pet plants, which had been distributed as a solution to prevent solitary deaths and depression among seniors living alone, are now expanded to help resolve the social isolation of the general public suffering from COVID-19. The new term "plant butler' became a new trend, and there was a change in the trend in which people shared their hobbies and information about pet plants and communicated with others in online.

Conclusion: Based on these findings, the trend data of pet plants before and after the outbreak of COVID-19 can provide the basis for activating research on pet plants and setting the direction for development of related industries considering the continuous popularity and trend of indoor gardening and green hobby.

Keywords: pet plants, topic modeling, latent dirichlet allocation (LDA), house plants, big data

\section{Introduction}

Mental health issues of individuals have been raised with the constraints on leisure due to social distancing and concerns of infection in the COVID-19 pandemic, and the longer time spent working from home increased interest in improving the residential environment, which drew attention to 'pet plants' (Kim, 2021; Hana Institute of Finance,
2020). Pet plants refer to raising and communing with plants by adding the concept of pets to the concept of gardening and hobby, and they are easily to purchase or manage as a medium that fulfills the need for communication (Kim, 2021; Kim and Cho, 2018a). Pet plants had been receiving attention as a solution to many social problems even before COVID-19, such as stabilizing emotions and preventing lonely deaths of middle-aged singles or seniors

Received: September 29, 2021, Revised: October 23, 2021, Accepted: November 7, 2021

First author: Yumin Park, cocoyumin@naver.com, (1) https://orcid.org/0000-0002-8483-3290

*Corresponding author: Yong-Wook Shin, ywsynn@gnu.ac.kr, (1) https://orcid.org/0000-0002-4983-0107 
living alone, thus widely used in local government supply projects. Since pet plant is a newly coined word that only began to be widely used since 2018 , there is little research adopting that term or concept. However, studies have been conducted continuously from various aspects for a long time on psychological and physical benefits of direct contact or interaction with plants, such as plant growing or gardening experience (Kim and Cho, 2018b).

Ju et al. (2020) discovered that taking care of pet plants has a positive effect on emotions such as promoting mental health, reducing loneliness, and improving life satisfaction. Deng and Deng (2018) claimed that growing plants indoors affects work performance, health, and stress; and since humans form close relationships with nature, bringing nature into an indoor space effectively improves communion with nature, which increases stability and helps promote psychological health. El-Tanbouly et al. (2021) reported that indoor plants can be used as an environment-friendly indoor purification tool that can remove air pollutants and microorganisms and purify the air, which helps reduce the spread of virus in closed indoor space. Kim et al. (2019) revealed that people growing plants indoors show greater interest in quality of life, life satisfaction, and interest in both general and indoor plants than others, and that greater interest in quality of life led to an increase in life satisfaction as well as interest in general and indoor plants.

The ongoing COVID-19 pandemic dramatically increased people's attention to health and green hobby, which led to a $10.5 \%$ increase in online attention to flowering plants in 2020 compared to the previous year, and the search amount of 'Monstera' increased by $71 \%$ in 2020 compared to 2019 (Hana Institute of Finance, 2020; EPIS, 2020). Pet plants have become the object of communion and contact that forms a great bond and stability, providing physical and mental repose as well as a sense of achievement and biophilia in the process of growth (KOTRA, 2019; Kim, 2019).

The increase in single-person households and the constraints on social activities to minimize infection cause mental health problems such as loneliness, anxiety, and depression, which has a severe effect on the quality of life as well (Lee and Lee, 2018; Hoffart et al., 2020). To solve these social problems, studies have been conducted since the outbreak of COVID-19, such as the study conducting a survey that determined how the COVID-19 pandemic and existence of flower pots at home affect anxiety, anger, fear, hypersensitiveness, and sleep disorder (Spano et al., 2021), the study identifying social isolation and the effect of nature deficit and subjective well-being (Tomasso et al., 2021), and the study revealing the relationship between the changing life due to social distancing and lockdown and non-human life such as plants at home (Vimal, 2021). However, there is insufficient research on the trend of 'pet plants' and how they are perceived by the public before and after COVID-19. Therefore, this study is conducted to analyze the changing trends in pet plants before and after COVID-19 and provide basic data for active research and development of pet plants.

\section{Research Methods}

\section{Data collection and purification}

Naver News that began distributing online news since May 2000 is a portal news website with the biggest number of users among all online news media, adopting the service that it merely receives news produced by other news media and delivers to the users instead of actually producing the news (Korea Press Foundation, 2020; Kim, 2014). This study collected articles on 'pet plants' using the detailed search of Naver News that shows the news data of major media companies at a glance as universal data used by a majority of people.

First, for data collection, Selenium of Python 3.9 (Pycon, USA) was used for crawling of news articles including the keyword 'pet plant' on Naver News by dividing the period into January 1, 2018 to August 15, 2019 (before COVID-19) and January 1, 2020 to August 15, 2021 (during COVID-19). After eliminating redundant data, we selected total 2,016 articles for analysis: 609 before COVID-19, and 1,407 during COVID-19.

\section{Method of analysis}

The texts were tokenized to purify the data of the finally selected articles, extracting nouns using Okt morphological 


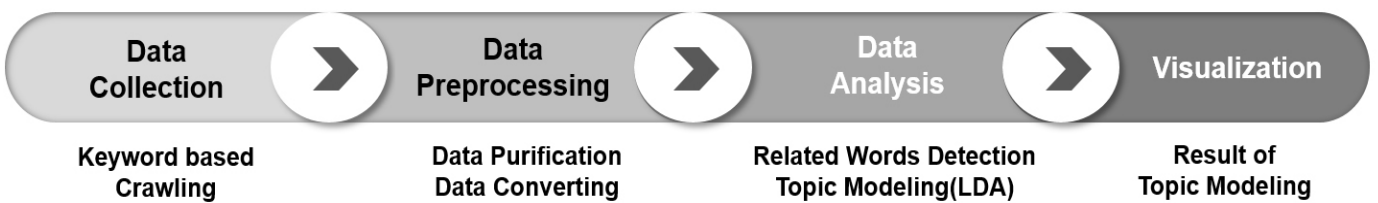

Fig. 1. Data analysis flowchart.

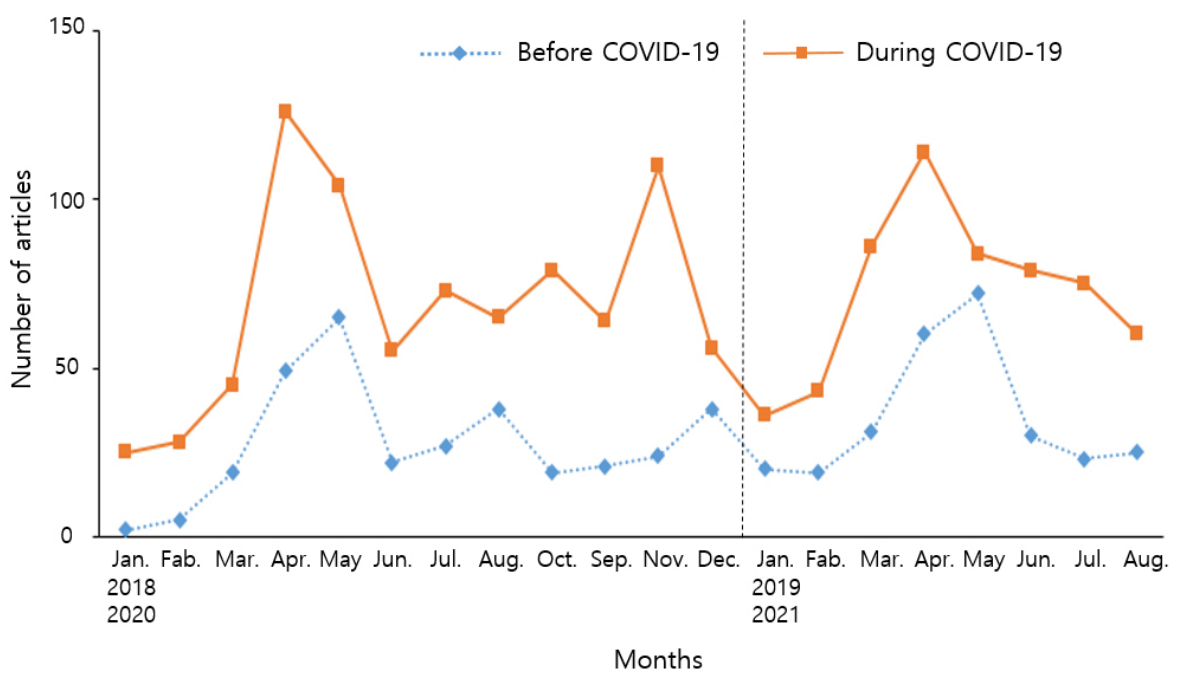

Fig. 2. Monthly count of articles mentioning 'pet plant' before and during COVID-19.

analysis on Python KoNLPy. Unlike English, Korean words cannot be divided based on spaces, which is why it is appropriate to identify keywords by extracting nouns, verbs, and adjectives with meaning (Park and Lee, 2021). Next, we set the frequency of two or more words at 10 or higher and converted frequently used words like 'fine' and 'dust' into a compound noun like 'fine dust', eliminated the stop words, and conducted a frequency analysis to identify major related keywords.

We measured perplexity and topic coherence to calculate the adequate number of topics. Then, topic modeling was conducted using Latent Dirichlet Allocation (LDA), which is a statistical text processing method (Blei and Lafferty, 2009) that deduces topics by clustering text keywords according to probability of occurrence and distribution in the document set. Topic modeling includes latent semantic indexing (LSI), probabilistic latent semantic analysis (pLSA), and LDA algorithms. LDA algorithms first proposed by Blei rt al. (2003) have utility in reducing data dimensions and can create semantically coherent topics (Mimno and McCallum, 2008). They also extract topics clearly and find the semantic relationship more easily, thus very useful in online text analysis (Nam, 2016). Accordingly, this study applied LDA topic modeling in identifying the inherent meanings of keywords relate to 'pet plant' and named the topics of each group. This analysis was conducted using Tidytext of Topicmodels in statistical software R 4.1.1, and the results of $\beta$ extracting the probability of words by topic were visualized (Fig. 1).

\section{Results and Discussion}

\section{Analysis of keywords related to pet plants before and after the COVID-19 outbreak}

We analyzed 2,016 (before COVID-19: 609, during COVID-19: 1,407) news articles (Fig. 2) ultimately selected with the keyword 'pet plant' from January 1, 2018 to August 15, 2019 (before COVID-19) and January 1, 2020 to August 15, 2021 (during COVID-19), and came up with total 63,597 words. The top 30 frequent keywords in the articles by period are as shown in Table 1, which is visualized into a word cloud in Fig. 3. Word cloud is 
Table 1. Top 30 frequent keywords of 'pet plant' in online news articles before and during COVID-19 pandemic

\begin{tabular}{|c|c|c|c|c|c|c|c|c|c|c|c|}
\hline \multicolumn{6}{|c|}{ Before COVID-19 (No. of articles : 609) } & \multicolumn{6}{|c|}{ During COVID-19 (No. of articles : 1,407) } \\
\hline No. & Keywords & Freqz & No. & Keywords & Freq & No. & Keywords & Freq & No. & Keywords & Freq \\
\hline 1 & Pet plants & 2,483 & 16 & Succulent plants & 160 & 1 & Pet plants & 11,125 & 16 & Family & 1,068 \\
\hline 2 & Gardens & 568 & 17 & Seniors living alone & 155 & 2 & COVID-19 & 4,437 & 17 & Dementia & 1,039 \\
\hline 3 & Experience & 306 & 18 & Mind & 150 & 3 & Healing & 2,491 & 18 & Cure & 1,037 \\
\hline 4 & City & 264 & 19 & Start & 148 & 4 & Stay at home & 2,364 & 19 & Supervision & 1,023 \\
\hline 5 & Flower pot & 211 & 20 & Indoors & 140 & 5 & Gardens & 2,165 & 20 & Happiness & 1,000 \\
\hline 6 & Elders & 200 & 21 & Welfare & 137 & 6 & Support project & 2,088 & 21 & Planterior & 982 \\
\hline 7 & Spaces & 198 & 22 & Purification & 135 & 7 & Elders & 1,950 & 22 & Emotional support & 944 \\
\hline 8 & Health & 194 & 23 & Environment & 135 & 8 & Distribution & 1,539 & 232 & Kits & 942 \\
\hline 9 & Urban agriculture & 191 & 24 & Emotion & 131 & 9 & Flower pot & 1,510 & 24 & Home & 926 \\
\hline 10 & Family & 189 & 25 & Attention & 128 & 10 & Welfare & 1,281 & 25 & Environment & 923 \\
\hline 11 & Vulnerable group & 179 & 26 & Happiness & 127 & 11 & Health & 1,279 & 26 & Plant butler & 921 \\
\hline 12 & Supervision & 168 & 27 & Home & 127 & 12 & Experience & 1,259 & 27 & Vulnerable group & 877 \\
\hline 13 & Fine dust & 165 & 28 & Treatment & 126 & 13 & Mind & 1,241 & 28 & Online & 865 \\
\hline 14 & Interior & 165 & 29 & Volunteer work & 121 & 14 & Depression & 1,173 & 29 & Urban agriculture & 861 \\
\hline 15 & Future & 162 & 30 & Lonely deaths & 117 & 15 & Psychology & 1,129 & 30 & Seniors living alone & 826 \\
\hline
\end{tabular}

${ }^{\mathrm{z}}$ Freq: Frequency.

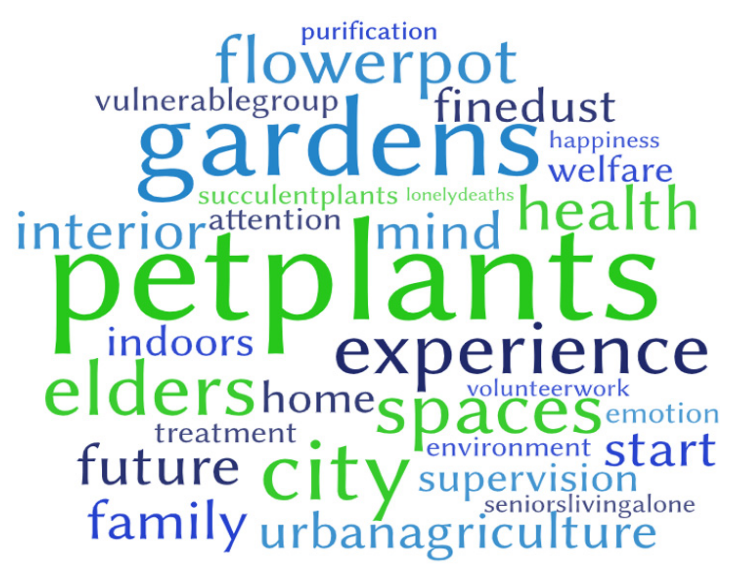

(A) 2018.01.01. - 2019.08.15.

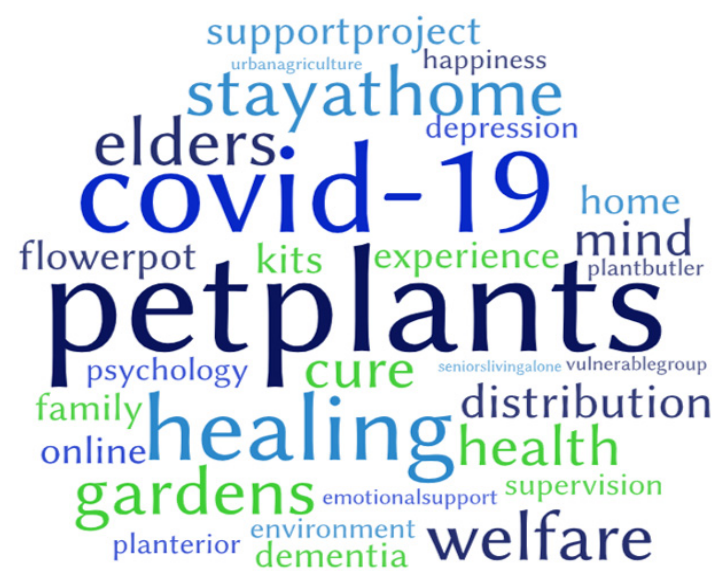

(B) 2020.01.01. - 2021.08.15.

Fig. 3. Word clouds of 30 frequently mentioned keywords before (A) and during (B) COVID-19.

a text mining technique that simply and visually shows the texts, presenting words in different sizes based on frequency or importance so that words emphasized in the document can be identified at a glance (Heimerl et al., 2014).

The top 30 frequent keywords before COVID-19 were pet plants $(2,483)$, gardens (568), experience (306), city (264), and flower pot (211), and the top 30 frequent keywords during COVID-19 were pet plants $(11,125)$, COVID-19 $(4,437)$, healing $(2,497)$, stay at home $(2,165)$, and gardens
$(2,165)$. Compared to 2018-2019 before the COVID-19 outbreak, the number of news articles using pet plant as a keyword showed a 130\% increase in 2020-2021. Pet plants, which have been receiving attention as an alternative to social problems such as elders, urban agriculture, and vulnerable groups and to environmental problems such as fine dust and purification, have been expanding the scope to mental health such as mind, depression, emotional support, and psychology as well as indoor spaces and hobbies such as 
Table 2. Results of Latent Dirichlet Allocation (LDA) Topic Modeling before and during COVID-19

\begin{tabular}{|c|c|c|c|c|c|c|}
\hline \multirow{2}{*}{$\begin{array}{l}\text { Keywords and } \\
\text { topics }\end{array}$} & \multicolumn{3}{|c|}{ Before COVID-19 (2018.01.01.- 2019.08.15.) } & \multicolumn{3}{|c|}{ During COVID-19 (2020.01.01.- 2021.08.15.) } \\
\hline & Topic 1 & Topic 2 & Topic 3 & Topic 1 & Topic 2 & Topic 3 \\
\hline \multirow{20}{*}{$\begin{array}{l}\text { Top-60 most } \\
\text { relevant } \\
\text { keywords }\end{array}$} & Pet plants & Elders & Interior & Pet plants & Elders & Home \\
\hline & Experience & Welfare & Indoors & COVID-19 & Support project & Environment \\
\hline & Urban agriculture & Supply & Planterior & Mask & Distribution & Gardens \\
\hline & Gardening & Seniors living alone & Environment & Daily life & Vulnerable group & Indoors \\
\hline & Trends & Loneliness & Design & Healing & Seniors living alone & Online \\
\hline & Resources & Supervision & Spaces & Emotional support & Family & Urban agriculture \\
\hline & Gardens & Treatment & Cure & Social distancing & Welfare & Vegetable garden \\
\hline & City & Volunteer work & Botanical cafe & Stress & Experience & Planterior \\
\hline & Future & Lonely deaths & Purification & Health & Supervision & Nature \\
\hline & Nature & Health & Home & Kits & Mind & Flowers pot \\
\hline & Trees & Family & Happiness & Stay at home & Program & Effort \\
\hline & Parks & Vulnerable group & Fragrance & Prevention & Isolation & Stability \\
\hline & Smart & Depression & Mind & Spread & Attention & Happiness \\
\hline & Daily life & Stability & Start & Psychology & Dementia & Interior \\
\hline & Flowers & Friends & Potted plant & Depression & Counseling & Hobby \\
\hline & Succulent plants & Exchange & Psychology & Refection & Treatment & Plant butler \\
\hline & Cactus & Effort & Healing & Cure & Stability & Concentration \\
\hline & Popularity & Communication & Green & Overcome & Package & Love \\
\hline & Flower pot & Emotion & Seeds & Disaster & Consolation & Gardening \\
\hline & Fine dust & Attention & Mood & Quarantine & Medical treatment & Communication \\
\hline Title of topics & $\begin{array}{l}\text { Pet plants } \\
\text { in daily life }\end{array}$ & $\begin{array}{l}\text { Pet plants and } \\
\text { welfare }\end{array}$ & $\begin{array}{c}\text { Pet plants and } \\
\text { hobbies }\end{array}$ & $\begin{array}{l}\text { Pet plants } \\
\text { in daily life during } \\
\text { social distancing }\end{array}$ & $\begin{array}{c}\text { Pet plants and } \\
\text { welfare } \\
\text { during COVID-19 }\end{array}$ & $\begin{array}{l}\text { Pet plants and } \\
\text { hobbies during } \\
\text { COVID-19 }\end{array}$ \\
\hline Proportion & $37.6 \%$ & $33.2 \%$ & $29.2 \%$ & $41.7 \%$ & $28.1 \%$ & $30.2 \%$ \\
\hline
\end{tabular}

planterior and plant butler during the COVID-19 pandemic, which is a noticeable trend.

\section{LDA topic modeling analysis on pet plants before and after the COVID-19 outbreak}

We first measured perplexity and coherence to identify the key topics and meanings of online news articles on pet plants. Perplexity shows high values when there is low satisfaction with the results in a probability distribution model and low values when there is high satisfaction, and thus the optimum number of topics in LDA has low perplexity (Lee, 2016). For coherence, which evaluates the similarity of top frequency words including the topics, higher scores indicate that each topic is comprised of semantically similar words (Newman et al., 2010). In this study, perplexity scores were -6.43 and -7.18 , and coherence scores were 0.51 and 0.47 before and after the COVID-19 outbreak when there are three topics, based on which 20 keywords were selected for each of the three topics (Table 2), and the results of extracting the probability of the keywords were visualized (Fig. 4).

The keywords related to pet plants in each topic before the COVID-19 outbreak are as follows. The top words in Topic 1 were 'pet plants', 'gardens', 'smart', 'trends', 'succulent plants', 'gardening', 'cactus', etc. As pet plant gardening and experience became a trend as part of urban agriculture, people are growing pet plants by bringing pots of succulent plants and cacti indoors in daily life. Words such as 'fine dust', 'future', 'nature', etc. showed people's interest in health and environment. Thus, Topic 1 was named 'Pet Plants in Daily Life'. 
(A)
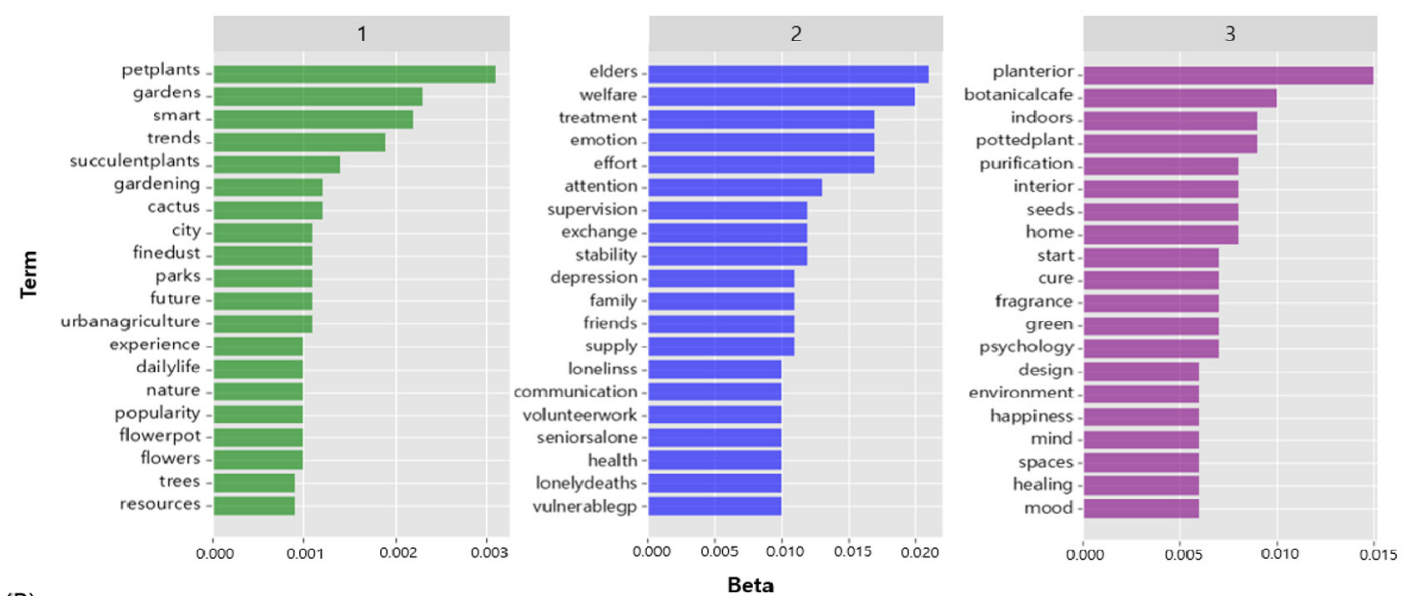

(B)
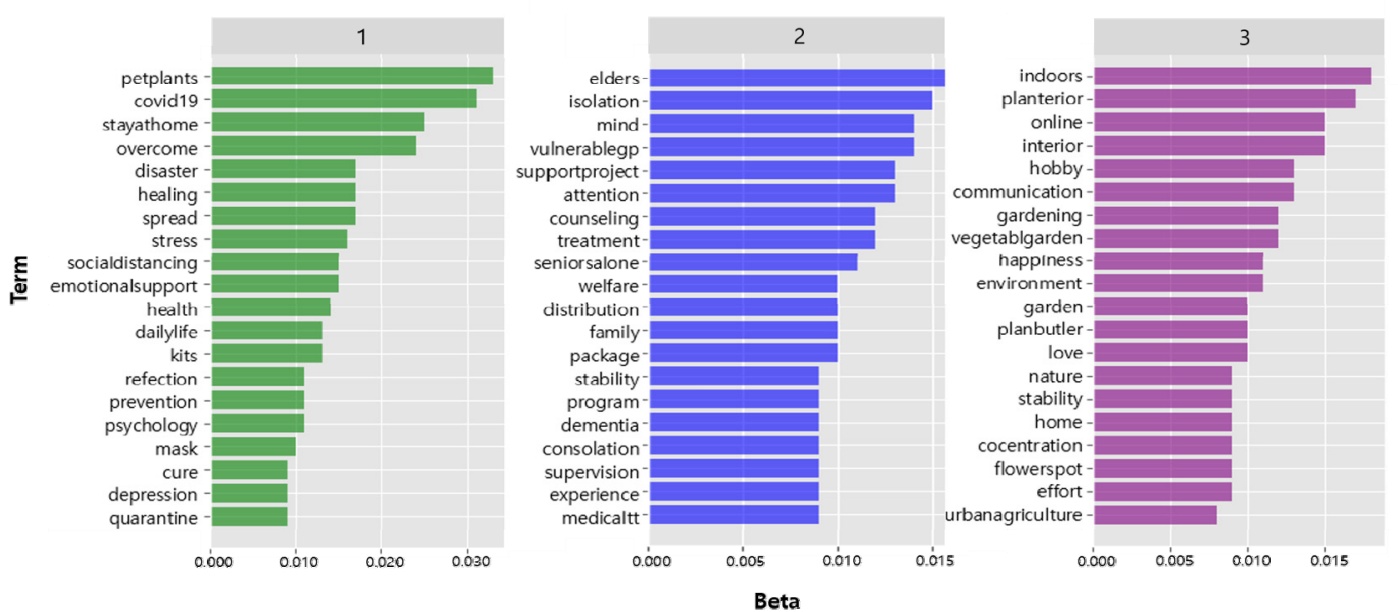

Fig. 4. The per-topic-per-word probabilities produced by latent Dirichlet allocation by extracting the beta matrix before (A) and during (B) COVID-19. Abbreviations: seniorsalone, seniors living alone; vulerrablegp, vulnerable group; medicaltt, medical treatment.

The top words in Topic 2 were 'elders', 'welfare', 'treatment', 'emotion', 'effort', 'supervision', 'attention', etc. There was an active pet plant supply project for vulnerable groups and socially isolated households to recover their physical and mental health by communing with pet plants. Keywords such as 'depression', 'lonely deaths', 'exchange', 'communication', 'friends', and 'family' particularly showed that pet plants for seniors living alone enabled communication and exchange with living things, thereby promoting emotional stability as a friend and family. Thus, Topic 2 was named 'Pet Plants and Welfare'.

The top words in Topic 3 were 'planterior', 'botanical cafe', 'indoors', 'potted plant', 'interior', etc. With the increasing attention and hobbies related to home interior and plants, a new word 'planterior' was coined, combining 'plant' and 'interior' (Lee and Park, 2019). Words such as 'spaces', 'purification', 'home', 'mood', etc. showed the trend in improving the living environment with pet plants to obtain air purification effect, psychological stability, and change of atmosphere by decorating the indoor space with plants. Thus, Topic 3 was named 'Pet Plants and Hobbies'.

The keywords related to pet plants in each topic during COVID-19 are as follows. The top words in Topic 1 were 'pet plants', 'COVID-19', 'stay at home', 'overcome', 'disaster', 'healing', 'spread', etc. Pet plants are receiving attention as an alternative for healing and emotional support in social distancing due to the COVID-19 pandemic. Words such as 'stress', 'psychology', 'refection', etc. showed that pet 

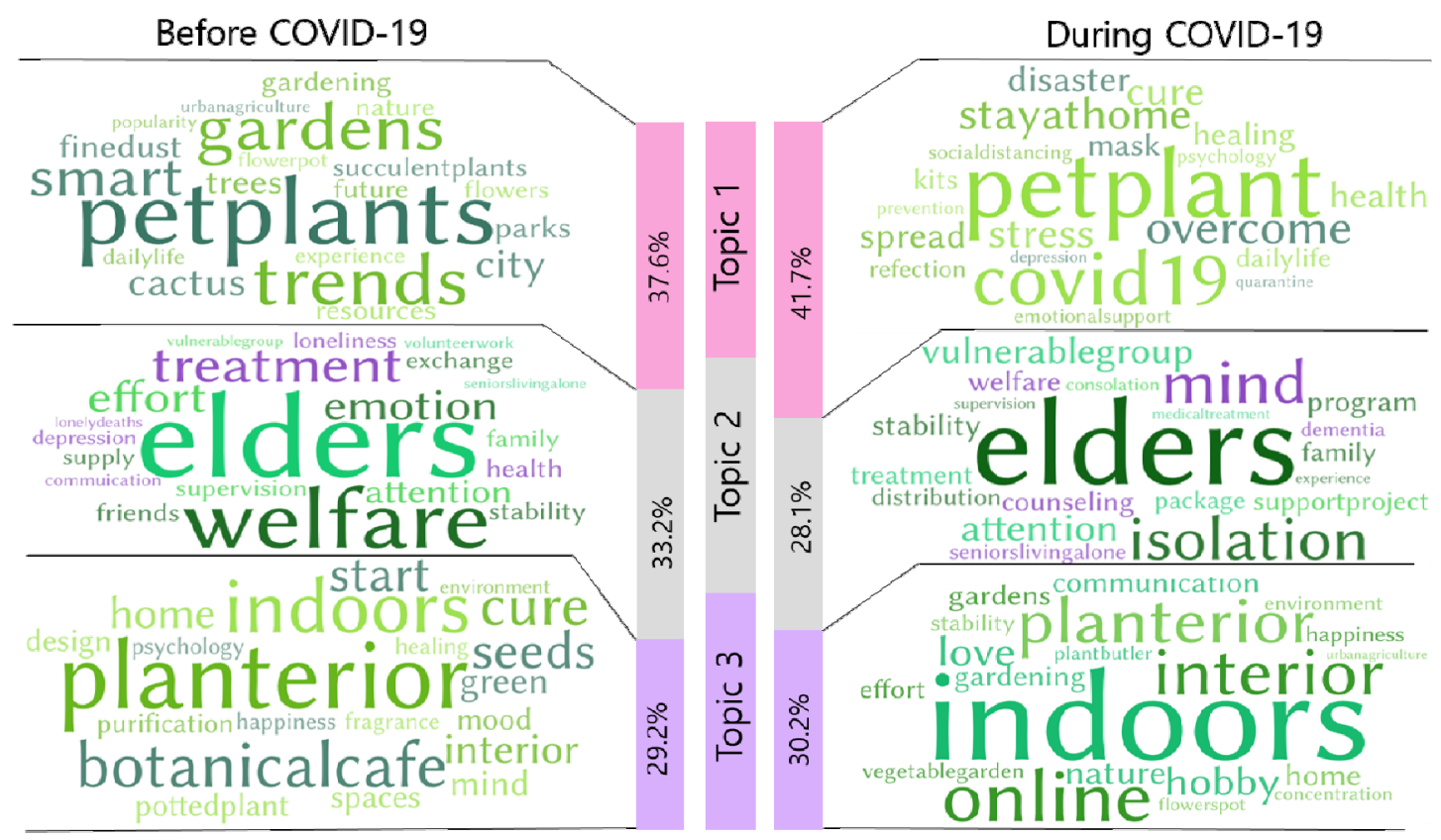

Fig. 5. Word cloud showing top 20 most relevant terms for each topics before and during COVID-19.

plants have a psychological effect on refection and stress relief for people staying at home on a daily basis. Thus, Topic 1 was named 'Pet Plants in Daily Life During Social Distancing'.

The top words in Topic 2 were 'elders', 'isolation', 'mind', 'vulnerable group', 'support project', 'attention', 'counseling', etc. The pet plant supply project for the middle aged and seniors living alone since before COVID-19 is still carried out continuously. Words such as 'refection', 'quarantine', 'overcome', etc. showed that this support project is actively carried out by each local government as a solution to social problems such as helplessness and depression of seniors living alone and vulnerable groups that are even more isolated due to social distancing in the COVID-19 pandemic. Thus, Topic 2 was named 'Pet Plants and Welfare During COVID-19'.

The top words in Topic 3 were 'indoors', 'planterior', 'online', 'interior', 'hobby', 'communication', 'gardening', 'vegetable garden', etc. People were carrying out gardening activities such as vegetable gardens to create a pleasant indoor environment at home and sharing their hobby or information on pet plants online. In particular, considering that there is a new word 'plant butler' that had not been found before COVID-19 appeared as one of the top words along with 'happiness', 'love', and 'communication', there seemed to be a trend in sharing communion and communication with pet plants with others. Thus, Topic 3 was named 'Pet Plants and Hobbies During COVID-19' (Fig. 5).

Pet plants in the three topics before the COVID-19 outbreak were used as a means to promote urban agriculture and take care of health, stabilize emotions, and improve the residential environment for seniors living alone that are exposed to various social problems (Seoul Metropolitan government, 2018). Moreover, as the attention to and popularity of cacti and succulent plants for air purification led to botanical cafés and interior decorations using plants, 'planterior' has emerged as a trend related to pet plants. This is in line with the results of a previous study proving that, as growing plants received attention due to the planterior craze and for promotion of physical and mental health, the demand for pet plants that provide emotional stability is rapidly increasing (Yoo, 2020).

There are also three topics during COVID-19, showing that the constraints on activities due to COVID-19 led pet plants to receive more attention as a 'healthy daily life' and 'healthy hobby' in social distancing where 'staying at home' has become a routine. The word 'plant butler' in particular is a new word referring to someone who grows 
and takes care of pet plants, and its use is constantly increasing not only in news articles related to pet plants but also on social network since the COVID-19 pandemic (Park, 2020). This is the same pattern as the global trend in words such as 'plant parenting', 'plant parenthood', and 'plant parent' meaning that people grow plants like a child. This reflects the value of treating a pet plant not just as an indoor plant but as a companion with which people can empathize, commune, and interact (Kim and Cho, 2018) in addition to sharing a bond by taking care of it close by.

This result is in line with previous studies claiming that growing plants helps meet emotional and mental needs and improve emotional stability, thoughtfulness, and bonds (Matsuo, 2004; Woo et al., 2012). This implies that taking care of pet plants is perceived as nurturing life, which affects emotional changes such as sense of achievement, self-esteem, and stability, thereby being widespread as a trend today.

\section{Conclusion}

This study conducted LDA topic modeling based on 2,016 online news articles using the keyword 'pet plant' to analyze the changes in the trends of pet plants before and after the COVID-19 outbreak and provide basic data on active research and development for studies on pet plants in the future.

The changes in the trends of pet plants before and after the COVID-19 outbreak based on the topic modeling results can be summarized as follows. First, pet plants in daily life that had been receiving attention as a gardening activity in urban agriculture have now become the object of 'emotional support' and 'healing' in this life of social distancing and quarantine brought by the COVID-19 pandemic. Second, pet plants that had been used in social welfare projects for the middle aged or seniors living alone as a solution to social problems such as lonely deaths and depression are now expanded to a support project to solve social isolation and heal the minds of the general public suffering 'corona blue' due to the prolonged pandemic. Third, the planterior craze, decorating indoor space with pet plants along with the growing interest in environmental problems and interior decorations, is expanded to healthcare and hobbies after the COVID-19 outbreak, causing the new word 'plant butler' to receive attention as a keyword. Moreover, there was a change in the trend where people shared their hobbies and information about pet plants online and communicated with others.

These results show that plant-related trends before COVID-19 that had been focused on 'gardening' such as urban agriculture and horticultural activities are now expanded to pet plants involving the concepts of communion, bond, and nurturing since the pandemic. In particular, as growing pet plants became a trend in social distancing, there is a rapid increase in so-called 'plant butlers' who communicate the entire process online from plant selection to seed germination and nurturing, and the information demanded by them is also increasing in diversity. This trend implies that there must be research paying attention to the stream of times since pet plants are spreading into various industrial sectors such as curation, plant hotels, and plant hospitals. In particular, considering that the plant market growth is led by the millennials interested in health, environment, and self-discipline, it is necessary to develop platforms or media reflecting the online trend of sharing daily life with pet plants. This will facilitate the expansion into relevant fields such as recording growth of pet plants, plant counseling such as varieties and diseases and pests, and customized plant consulting.

Having identified the trends of pet plants in online news articles before and after the COVID-19 outbreak, this study is expected to have utility value as important grounds in promoting research on pet plants and setting the direction for relevant industrial development considering the constant popularity and trend in indoor gardening and green hobby. However, this study has the following limitations. First, only Naver News was used to collect research data. It would be possible to more closely analyze the trend by adding social media data such as Instagram or Facebook with many users where real-time communication is possible. Second, the passage of time is divided only into before and after the COVID-19 outbreak. By subdividing the period into the first through fourth resurgences of COVID-19 or in quarters, it would be possible to come up with keywords that match each topic more precisely. 
Third, we used only the titles and main texts of news articles for topic modeling analysis. An emotion analysis on comments for the news articles will help empirically analyze the diverse changes in trends as well as the public awareness, emotions, and attitudes toward pet plants.

\section{References}

Blei, D.M., A.Y. Ng, and M.I. Jordan. 2003. Latent dirichlet allocation. J. Mach. Learn. Res. 3:993-1022.

Blei, D.M. and J.D. Lafferty. 2009. Topic models. In A.N. Srivastava and M. Sahami (eds). Text mining (pp. 101-124). New York, USA: Chapman and Hall/CRC. Retrieved from http://machinelearningtext.pbworks.com /w/file/fetch/47924743/BleiLafferty2009.pdf

Deng, L. and Q. Deng. 2018. The basic roles of indoor plants in human health and comfort. Environ. Sci. Pollut. Res. 25:36087-36101. https://doi.org/10.1007/s11356-0183554-1

El-Tanbouly, R., Z. Hassan, and S. El-Messeiry. 2021. The role of indoor plants in air purification and human health in the context of COVID-19 pandemic: A proposal for a novel line of inquiry. Front. Mol. Biosci. 8:624. https://doi.org/10.3389/fmolb.2021.709395

EPIS (Korea Agency of Education, Promotion and Information Service in Food, Agriculture, Forestry and Fisheries). 2020, December 28. 'Flower interest' rises after Covid-19, purchases for interior purposes increase. Retrieved from https://www.epis.or.kr/board/read?boardManagementNo $=19 \&$ boardNo $=8857 \&$ searchCategory $=\&$ page $=1 \&$ searc hType $=$ total $\&$ level $=2 \&$ menuNo $=28$

Hana Institute of Finance. 2020. December 16. Changes in consumer behavior due to "Covid-19" II . Retrieved from http://www.hanaif.re.kr/boardDetail.do?hmpeSeqNo $=3466$

Heimerl, F., S. Lohmann, S. Lange, and T. Ertl. 2014. January 6-9. Word cloud explorer: text analytics based on word clouds. 47th Hawaii International Conference on System Sciences. 1833-1842. Hawaii, USA. https:// doi.org/10.1109/HICSS.2014.231

Hoffart, A., S.U. Johnson, and O.V. Ebrahimi. 2020. Loneliness and social distancing during the COVID-19 pandemic: Risk factors and associations with psychopathology.
Front. Psychiatry 11:1297. https://doi.org/10.3389/fpsyt. 2020.589127

Ju, Y.S., S.Y. Han, and Y.J. Park. 2020. Effects of companion plants on mental health of elderly women living alone in the city. J. Korean Inst. Gard. Design. 6(3): 218-227. https://doi.org/10.22849/jkigd.2020.6.3.002

Kim, D.W. 2021. March 22. Pet plants attract attention as a new trend after COVID-19. KB Management Research Institute. Seoul, Korea: Retrieved from https://www. $\mathrm{kbfg} . \mathrm{com} / \mathrm{kbresearch} / \mathrm{vitamin} /$ reportView.do?vitaminId $=2000281$

Kim, H.S. and T.D. Cho. 2018a. Psychological effects of pet plant gardening on university students. J. Environ. Sci. Int. 27(4):267-274. https://doi.org/10.5322/JESI.2018. 27.4.267

Kim, H.S. and T.D. Cho. 2018b. Determining emotional effects of pet plants through analysis of daily gardening records. J. Environ. Sci. Int. 27(9):789-796. https://doi.org/10.5322/JESI.2018.27.9.789

Kim, M.J. 2019, August 16. Why are Millennials crazy about green plants?. Ilyo Newspaper. Retrieved from https://www.ilyo.co.kr/?ac=article_view\&entry_id $=344588$

Kim, W.G. 2014. The influence of portal site news services on online journalism in Korea: The structural transformation or the power change in the news distribution. Korean J. Commun. Inf. 66:5-27. https://www.koreascience.or.kr/article/JAKO201418942861897.page

Kim, Y., J.W. Hong, and J. Kim. 2019. Life satisfaction and the perception of plants are increased by growing indoor plants. Flower Res. J. 27(1):42-50. https://doi.org/10.11623/frj.2019.27.1.07

Korea Press Foundation. 2020. Media users in Korea 2020. Retrieved from https://www.kpf.or.kr/front/research/consumer Detail.do

KOTRA. 2019, September 20. Millennials are rapidly emerging as a major consumer group in the US gardening market. KOTRA Trend. Retrieved from https:// news.kotra.or.kr/user/globalBbs/kotranews/782/ globalBbsDataView.do?setIdx=243\&dataIdx=177459

Lee, D.G. and J.S. Lee. 2018. October 15. Issue Briefing. 181. The meaning of the loneliness care industry in the era of single-person households and the direction to promote Jeollabuk-do. Jeonbuk Research Institute. Retrieved 
from http://repository.jthink.kr/handle/2016.oak/487

Lee, H.N., H.N. Park, and J.K. Paik. 2019. A study on user's opinion for designing of multi-functional plant applications. Korean Soc. Sci. Art. 37(4):297-308. https://doi.org/10.17548/ksaf.2019.09.30.297

Lee, S.S. 2016. A study on the application of topic modeling for the book report text. J. Korean Libr. Inf. Sci. Soc. 47(4):1-18. https://doi.org/10.16981/kliss.47.4.201612.1

Matsuo, E. 2004. Humanity in horticulture-healing and pleasure. ISHS Acta Hortic. 790:39-44. https://doi.org/10.17660/ActaHortic.2008.790.3

Mimno, D.M. and A. McCallum. 2008. Topic models conditioned on arbitrary features with dirichlet-multinomial regression. In UAI. 24:411-418. Retrieved from http:// citeseerx.ist.psu.edu/viewdoc/download?doi=10.1.1. $366.9430 \&$ rep $=$ rep $1 \&$ type $=$ pdf

Nam, C.H. 2016. An illustrative application of topic modeling method to a farmers diary. Inst. Cult. Stud. 22(1): 89-135. Retrieved from https://hdl.handle.net/10371/95582

Newman, D., J.H. Lau, K. Grieser, and T. Baldwin. 2010. June. Automatic evaluation of topic coherence. Human Language Technologies: The 2010 Annual Conference of the North American Chapter of the Association for Computational Linguistics. pp.100-108. Retrieved from https://aclanthology.org/N10-1012.pdf

Park, S.H. 2020. May 26. If you are tired of staying at home, heal yourself with a pet plant. Donga Daily. Retrieved from https:/www.donga.com/news/article/all/ 20200526/101210578/1

Park, S.Y. and J.R. Lee. 2021. COVID-19 and Korean fam- ily life on social media: A topic model approach. J. Korea Content Assoc. 21(3):282-300. https://doi.org/10. 5392/JKCA.2021.21.03.282

Seoul Metropolitan Government, 2018, November 23. Seoul Metropolitan Government, distribution of pet plants' to reduce depression and loneliness to 2,000 single elderly people. Retrieved from https://news.seoul.go.kr/economy/archives/500417

Spano, G., M. D’Este, V. Giannico, M. Elia, R. Cassibba, R. Lafortezza, and G. Sanesi. 2021. Association between indoor-outdoor green features and psychological health during the COVID-19 lockdown in Italy: A cross-sectional nationwide study. Urban For. Urban Green. 62:127-156. https://doi.org/10.1016/j.ufug.2021. 127156

Tomasso, L.P., J. Yin, J.G. Cedeño Laurent, J.T. Chen, P.J. Catalano, and J.D. Spengler. 2021. The relationship between nature deprivation and individual wellbeing across urban gradients under COVID-19. Int. J. Environ. Res. Public Health 18(4):1511. https://doi.org/10.3390/ ijerph18041511

Vimal, R. 2021. The impact of the Covid-19 lockdown on the human experience of nature. Sci. Total Environ. 803:149571. https://doi.org/10.1016/j.scitotenv.2021.149571

Woo, J.A., S.B. Kim, and T.S. Park. 2012. The phenomenological study of plant-glowing experience. Korean J. Couns. 13(4):2033-2048. http://doi.org/10.15703/kjc. 13.4.201208.2033

Yoo, H.Y. 2020. A proposal of service design for companion plants utilizing open data. J. NCIST. 9(2):163173. http://doi.org/10.29056/jncist.2020.06.06. 